\title{
Abordagem multiprofissional no diagnóstico de leishmaniose: um relato de caso
}

\author{
Multiprofessional approach in the diagnosis of leishmaniosis: a case report \\ Enfoque multidisciplinario en el diagnóstico de la leishmaniasis: reporte de un caso \\ Cléa Adas Saliba GARBIN \\ Naiana de Melo BELILA \\ Igor Barcellos PRECINOTI \\ Simone MIYADA \\ Artênio José Ísper GARBIN \\ Ronald Jefferson MARTINS
}

Programa de Pós-Graduação em Odontologia Preventiva e Social,

Faculdade de Odontologia de Araçatuba, Universidade Estadual Paulista (UNESP), 16015-050, Araçatuba-SP, Brasil

\begin{abstract}
Resumo
Introdução: A Leishmaniose Tegumentar Americana (LTA) é uma doença crônica, grave, infecciosa e não contagiosa, sendo encontrada em quase toda a América Latina, afetando as populações autóctones e viajantes. Objetivo: Objetivouse elucidar a importância da equipe multiprofissional para a realização do diagnóstico definitivo, de um caso de Leishmaniose Tegumentar Americana. Caso clínico: Paciente de 74 anos, sexo masculino, procurou o serviço de saúde com queixa de rouquidão e odinofagia. Ao exame médico, apresentou lesão irregular em palato duro e mole com proeminências lobuladas e ulceradas. Foram solicitados teste rápido e sorologia cujos resultados foram negativos. Para confirmação diagnóstica, foi requerido no serviço odontológico a biópsia da lesão e o teste Reação de Polimerase em Cadeia. Conclusão: Salientamos a importância da integração médico odontológica para conclusão do diagnóstico e realização do tratamento.

Descritores: Leishmaniose; Leishmaniose Mucocutânea; Diagnóstico.
\end{abstract}

\begin{abstract}
Introduction: The American Cutaneous Leishmaniasis (LTA) is a chronic, serious, infectious and non-contagious disease, found in almost all of Latin America, affecting native populations and travelers. Objective: The objective of this study was to elucidate the importance of a multiprofessional team for the definitive diagnosis of a case of American Cutaneous Leishmaniasis. Clinical case: A 74-year-old male patient sought health services with complaints of hoarseness and odynophagia. At the medical examination, he presented an irregular lesion on his hard and soft palate with lobulated and ulcerated prominences. A rapid test and serology were requested, the results of which were negative. In order to performe a diagnostic confirmation, the lesion biopsy and the Chain Polymerase Reaction test were required at the dental service. Conclusion: We emphasize the importance of the dental-medical integration for the conclusion of the diagnosis and the accomplishment of the treatment.
\end{abstract}

Descriptors: Leishmaniasis; Mucocutaneous Leishmaniasis; Diagnosis.

\section{Resumen}

Introduccíon: La Leishmaniasis Cutánea Americana (LCA) es una enfermedad crónica, grave, infecciosas y no infecciosas y es responsable de casi toda América Latina, que afecta a las poblaciones indígenas y los viajeros. Objetivo: Este estudio tuvo como objetivo dilucidar la importancia del equipo multidisciplinario para llevar a cabo el diagnóstico definitivo de un caso de Leishmaniasis Cutánea Americana. Caso clinico: Paciente de 74 años, de sexo masculino, buscó el servicio de salud quejándose de ronquera y dolor de garganta. En el examen médico mostró lesión irregular en el paladar duro y blando con prominencias lobulados y ulceradas. Se solicitaron pruebas de serología y rápidos resultados de los cuales fueron negativos. Para la confirmación de diagnóstico se requería en la biopsia servicio dental de la lesión y la prueba de Polymerase Chain Reaction. Conclusión: Hacemos hincapié en la importancia de la integración de medicina dental para completar el diagnóstico y la finalización del tratamiento.

Descriptores: Leishmaniasis; Leishmaniasis Mucocutánea; Diagnóstico.

\section{INTRODUÇÃO}

A Leishmaniose Tegumentar Americana (LTA) é uma doença crônica, grave, infecciosa e não contagiosa, sendo encontrada em quase toda a América Latina, afetando as populações autóctones e viajantes. $\mathrm{O}$ agente etiológico é um protozoário da ordem Kinetoplastida, da família Trypanosomatidae e gênero Leishmania, que acomete pele e mucosas. A transmissão da LTA é através da picada de fêmeas flebotomíneos, da espécie Lutzomyialongipalpis, conhecidos popularmente, dependendo da localização geográfica, como mosquito palha, tatuquira e birigui ${ }^{1}$, onde o Canis lupusfamiliaris, o cão, é o principal reservatório desta doença ${ }^{2}$.

A doença apresenta-se na forma cutânea ou mucosa ${ }^{3}$, sendo que a apresentação mucosa é na maioria das vezes secundária às lesões cutâneas, surgindo geralmente, meses ou anos após a resolução das lesões de pele ${ }^{1}$. Quando acometem a mucosa bucal, a doença se torna destrutiva ou ulcerovegetativa e granulomatosa, acompanhada pela presença de granulações grosseiras e sulcos profundos. Geralmente, a dificuldade de deglutir e a dor são os principais sintomas relatados, além de sialorréia, odor fétido e o sangramento ${ }^{4}$.

O diagnóstico da LTA é um desafio para a equipe de saúde, pois abrange aspectos epidemiológicos, clínicos e laboratoriais (pesquisa parasitológica e diagnóstico imunológico), além de possuir diversos diagnósticos diferencias como a paracoccidioidomicose, sífilis terciária, neoplasias, entre outros ${ }^{4}$. Vem sendo amplamente utilizado para fins de pesquisa o método molecular de Reação de Polimerase em Cadeia (PCR), que na rotina de diagnóstico, é 
pouco utilizado, porém acrescenta em sensibilidade quando associado aos métodos parasitológicos tradicionais ${ }^{1}$.

Mais de $90 \%$ dos casos mundiais da LTA ocorrem em Bangladesh, Índia, Sudão, Sudão do Sul, Etiópia e no Brasil, sendo que a sua incidência atualmente estimada é de cerca de 200.000 a 400.000 novos casos em todo o mundo. Porém estes dados são uma estimativa, devido muitos países não realizar uma correta vigilância, notificação e arquivamento de seus dados ${ }^{2}$. E mesmo com a grande incidência de casos subnotificados, $90 \%$ dos casos da América Latina estão no Brasil.

De acordo com o que é regido no decreto do Senado Federal $n^{\circ}$ 51.838, de 14 de março de 1963, a Leishmaniose é uma doença de notificação obrigatória considerada uma endemia rural ${ }^{5}$.

No ano de 2006 foi publicado pelo Ministério da Saúde, o Programa de Vigilância e Controle da Leishmaniose Visceral (PVCLC), que teve como intuito marcar o avanço territorial e diminuir a morbidade e letalidade da doença, com medidas baseadas no diagnóstico e tratamento precoce dos casos humanos, redução da população de flebotomíneos, eliminação de reservatórios e atividades de educação em saúde. No entanto, apesar dos esforços, identifica-se a expansão dos casos autóctones humanos e das áreas endêmicas urbanas de Leishmaniose no Brasil $^{6}$.

Em 2012, foram notificados no Brasil 3.038 casos da doença em humanos, com uma incidência da ordem de 1,57 para cada 100.000 habitantes com uma taxa de letalidade de $7,1 \%^{7}$.

Desta forma, o movimento de luta pela reforma sanitária no Brasil passou a ter uma dimensão social no processo saúde-doença, onde para compreender o processo em qualquer comunidade, faz-se necessário entender o ser humano no seu meio físico, biológico, social e econômico ${ }^{8}$.

Devido as lacunas que existem na identificação e notificação dos casos de Leishmaniose Tegumentar Americana, este trabalho teve por objetivo elucidar a importância da participação do cirurgião-dentista junto ao clínico geral e infectologista para a realização do diagnóstico definitivo, baseado em uma abordagem multiprofissional, de um caso de LTA, em mucosa bucal, com envolvimento gengival e de palato, em um paciente idoso.

\section{CASO CLÍNICO}

Paciente de 74 anos, sexo masculino, procedente de um município de médio porte do noroeste do Estado de São Paulo, Brasil, diabético, hipertenso, portador de doença renal crônica.

Procurou o serviço de saúde, onde foi atendido por um médico clínico geral, com queixa de rouquidão e odinofagia com início há 6 meses. Paciente negava quaisquer outras lesões cutâneas e afirmava não ter feito qualquer viagem. Foram prescritos anti-inflamatório e administrado Penicilina Benzatina, não havendo melhora.

Devido à piora dos sintomas, o paciente foi encaminhado ao serviço de vigilância epidemiológica do município, onde foi atendido por um médico infectologista.

Ao exame médico, apresentou lesão irregular em palato duro e mole com proeminências lobuladas e lesões ulceradas com presença de exsudação amarelada, se estendendo até a úvula (Figura 1). Foram solicitados teste rápido (rK39 antigen-based immunochromatographic test) e sorologia (Enzyme linked immunosorbent assay - ELISA) para Leishmaniose cujos resultados foram negativos.
Optou-se então por iniciar terapia antimicrobiana com Amoxicilina e Clavulanato.

A partir das lesões bucais encontradas, o paciente foi encaminhado ao serviço de odontologia para elucidação diagnóstica. No serviço odontológico foi proposta a realização de biópsia da lesão bucal e solicitado o PCR para Leishmaniose, onde não foram observados parasitos ou formas fúngicas ao exame direto e também não foram observados critérios histopatológicos para neoplasia (Figura 2). A terapêutica específica somente foi iniciada após resultado de PCR para Leishmania cujo resultado foi positivo para o segmento $120 \mathrm{pb}$ do DNA de Leishmania sp.

Considerando a idade do paciente e comorbidades optou-se pelo tratamento com Anfotericina B (Lipossomal), com dose total de $2500 \mathrm{mg}$. Paciente evoluiu com remissão total dos sintomas.

Após 5 meses de tratamento, paciente retornou novamente ao ambulatório referindo dor de garganta, odinofagia e perda ponderal de $2 \mathrm{~kg}$. Realizado nova biópsia, não foram encontradas formas fúngicas ou parasitos e novamente o diagnóstico só foi conclusivo após realização de PCR. O paciente então foi submetido a um novo tratamento com Anfotericina B (Lipossomal). Neste segundo evento foi optado realizar uma dose total de $3000 \mathrm{mg}$. O paciente apresentou remissão total dos sintomas e atualmente se mantém em acompanhamento ambulatorial a cada 60 dias, e não apresentou novas recidivas (Figura 3).

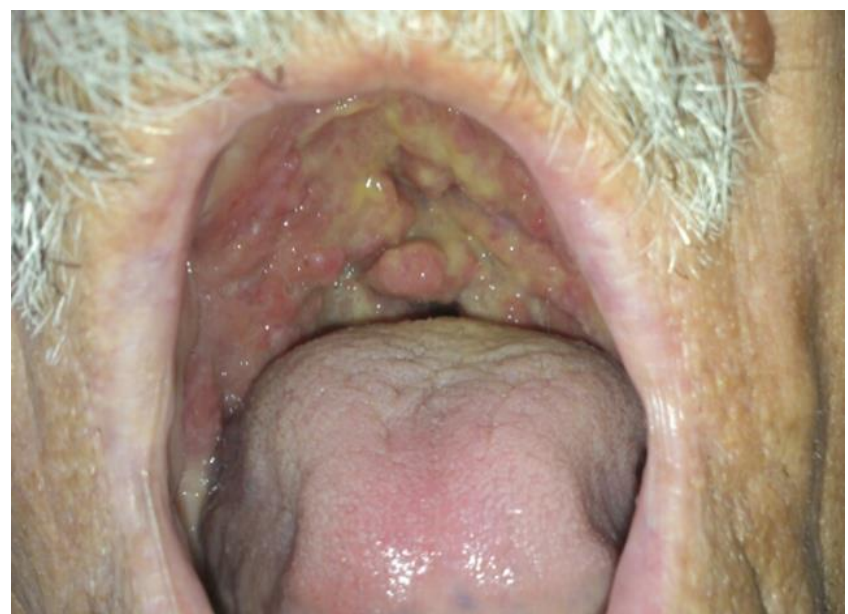

Figura 1: Aspecto clínico inicial das lesões bucais, Birigui, 2015.

PALATO MOLE: ANÁLISE MOLECULAR REVELANDO INDICIOS DE INFECÇĀO POR_LEISHMANIA SP_
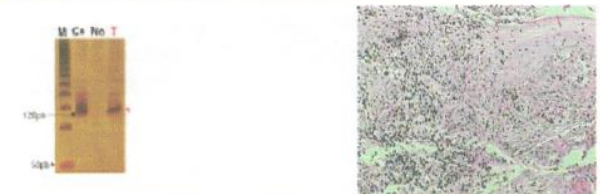

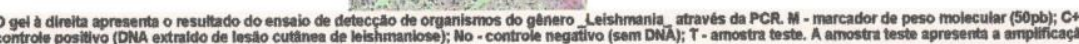

Figura 2: Resultado do PCR extraído a partir da lesão em palato que confirma a detecção do organismo e imagem histopatológica sem alterações sugestivas de neoplasia, Birigui, 2015.

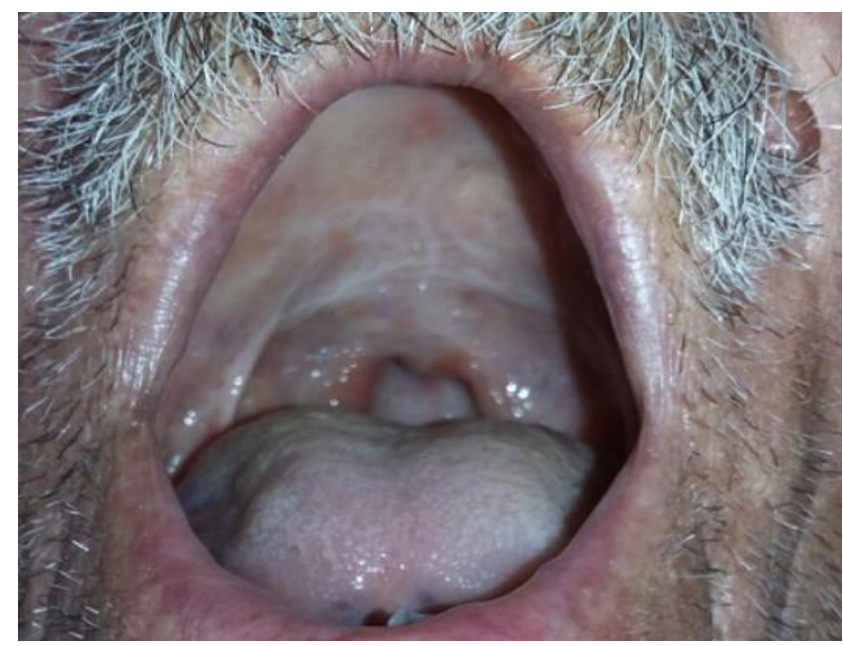

Figura 3: Acompanhamento 2 meses após segunda terapia medicamentosa, Birigui, 2015. 


\section{DISCUSSÃO}

A leishmaniose constitui um problema de saúde pública no Brasil e no mundo, sendo endêmica em 88 países e a segunda doença mais preocupante dentre as causadas por protozoários com relevância médica, superada apenas pela malária ${ }^{9}$. Apesar do comprometimento da mucosa nasal e/ou oral ser menos frequente que a forma cutânea, essa geralmente é a mais grave, podendo deixar grandes sequelas no indivíduo e levar ao óbito. O tempo de evolução da doença é dependente do fator biológico que irá determinar a disseminação do parasita, sendo um dos principais responsáveis pela proporção das lesões mucosas e suas consequências ${ }^{10}$.

Em relação aos aspectos clínicos das lesões encontradas no paciente relatado, outros estudos mostram as mesmas características, ou seja, lesões com aspecto ulcerovegetativo, com uma margem eritematosa, podendo ser confundida com outras lesões ${ }^{4,11,12}$. Poucos trabalhos relatam o envolvimento gengival na leishmaniose, sendo comumente descrito em pacientes HIV positivos e/ou indivíduos com a forma visceral da leishmaniose, assim como em pacientes com outros tipos de imunossupressão ${ }^{12}$.

Os casos de LTA com envolvimento da mucosa oral não são observadas com frequência pelos cirurgiõesdentistas em suas práticas clínicas de rotina, porém, a participação deste profissional no caso foi de extrema importância para que se chegasse ao diagnóstico correto e precoce da doença, através da biópsia realizada e da solicitação do PCR.

Outro estudo também mostrou de extrema importância a participação do cirurgião-dentista para o diagnóstico precoce de LTA para que não houvesse o agravamento das lesões. Pois apesar do paciente apresentar uma lesão ulcerovegetativa, ainda não havia destruição tecidual causada pela evolução da doença, especialmente nas regiões cutâneas e cartilaginosas da face, que poderiam deixar sequelas irreversíveis ${ }^{11}$.

Julga-se necessário que os cirurgiões-dentistas possuam conhecimento adequado e estejam atentos as manifestações bucais da LTA, para que desta forma ocorra o correto diagnóstico, solicitação adequada de exames e o encaminhamento para uma instituição de tratamento especializada. A interação do cirurgião-dentista com os profissionais das diferentes áreas da saúde e médica é de suma importância para o estabelecimento do diagnóstico diferencial desta doença ${ }^{13,14}$.

Muitos autores julgam como técnicas confiáveis para o diagnóstico da LTA a realização da biópsia da lesão e o exame histopatológico propriamente dito ${ }^{11,15,16,17,18}$. Porém o diagnóstico pode ser dificultado quando o paciente não reside em áreas endêmicas e também pela vasta possibilidade de diagnósticos diferenciais para as lesões ou pela inexperiência da equipe clínica responsável ${ }^{11}$.

Desta forma, ressaltamos a importância da abordagem multiprofissional e a participação do cirurgião-dentista no pedido do PCR para a elucidação diagnóstica e início do tratamento. $\mathrm{O}$ exame de PCR que permite amplificar em escala exponencial a sequência de DNA, identificando pequenas quantidades de DNA da leishmaniose, com especificidade de $95 \%$ e sensibilidade de $98 \%$ para diagnóstico da doença. Entretanto existe certa dificuldade na realização do exame no Sistema Único de Saúde (SUS) devido ao seu alto custo ${ }^{11,19}$.

Quanto ao tratamento, as drogas de primeira escolha na LTA são os Atimoniais Pentavalentes $(\mathrm{Sb}+5)^{20}$, e não havendo resposta satisfatória ou havendo contra indicações ao tratamento, as drogas de segunda escolha são a Anfotericina B e a Pentamidina ${ }^{1}$. No caso apresentado, após a confirmação diagnóstica pela biópsia, o caso foi conduzido por equipe médica em ambiente hospitalar, que optou por não realizar nenhum tratamento local, e neste caso, a forma Lipossomal da Anfotericina B foi o medicamento de escolha para o tratamento, por agir especificamente sobre célulasalvo (macrófagos), incorporando ao meio intracelular e assim reduzindo efeitos colaterais ${ }^{21}$. Porém, apesar da alta eficácia da Anfotericina ${ }^{22}$, este paciente apresentou episódio de recidiva, sendo necessário aumentar a dose do medicamento para sua total recuperação.

\section{CONCLUSÃO}

Desta forma, salientamos no caso apresentado a importância do trabalho multiprofissional entre a equipe de saúde médica e o cirurgião-dentista para se determinar o diagnóstico com eficácia. É imprescindível que os profissionais envolvidos sejam capazes de reconhecer as características das lesões em mucosa oral acometidas pela Leishmaniose, devido aos diversificados diagnósticos diferenciais. E apesar da dificuldade de diagnóstico, é de extrema importância que ele seja realizado o mais rápido possível, com o objetivo de definir o tratamento mais apropriado e evitar o comprometimento da mucosa nasal e oral do paciente.

\section{REFERENCIAS}

1. Ministério da Saúde do Brasil. Manual de Vigilância da Leishmaniose Tegumentar Americana. Brasília; 2010

2. Choi CM, Lerner EA. Leishmaniasis as an emerging infection. JID Symposium Proceedings. 2001; 6(3):175-82.

3. Palmeiro MR, Rosalino CM, Quintella LP, Morgado FN, da Costa Martins AC, Moreira J et al. Gingival leishmaniasis in an HIV-negative patient. Oral Surg Oral Med Oral Pathol Oral Radiol Endod, 2007; 104(6):e12-6.

4. Gontijo B, Carvalho MLR. Leishmaniose tegumentar americana. Rev Soc Bras Med Trop.2003;36(1):71-80.

5. Diniz JLCP, Costa MOR, Gonçalves DU. Mucocutaneous Leishmaniasis: clinical markers in presumptive diagnosis. Braz j otorhinolaryngol. 2011; 77(3):380-4.

6. Passos VMA, Barreto SM, Romanha AJ, Krettli AU, Volpini AC, Gontijo CMF et al. Leishmaniose tegumentar na Região Metropolitana de Belo Horizonte: aspectos clínicos, laboratoriais, terapêuticos e evolutivos (1989-1995). Rev Soc Bras Med Trop.2001;34(1):5-12.

7. de Vries HJ, Reedijk SH, Schallig HDFH. Cutaneous Leishmaniasis: Recent Developments in Diagnosis and Management. Am J Clin Dermatol. 2015;16(2):99-109.

8. Molinet FJ, Ampuero JS, Costa RD, Noronha EF, Romero GA. Specificity of the rapid rK39 antigen-based immunochromatographic test Kalazar Detect(r) in patients with cutaneous leishmaniasis in Brazil. Mem Inst Oswaldo Cruz. 2013;108(3):293-6.

9. Amato SV, Tuon FF, Siqueira AM, Nicodemo AC, Amato Neto V. Treatment of Mucosal Leishmaniasis in Latin America: Systematic Review. Am J Trop Med Hyg. 2007; 77(2):266-74.

10. Paula CDR, Sampaio JHD, Cardoso DR, Sampaio RNR. Estudo comparativo da eficácia de isotionato de pentamidina administrada em três doses durante uma semana e de N-metil-glucamina $20 \mathrm{mgSbV} / \mathrm{kg} / \mathrm{dia}$ 
durante 20 dias para o tratamento da forma cutânea da leishmaniose tegumentar americana. Rev Soc Bras Med Trop. 2003; 36(3):365-71.

11. Sampaio RN, Marsden PD. Treatment of the mucosal form of leishmaniasis without response to glucantime, with liposomal amphotericin B. Rev Soc Bras Med Trop. 1997; 30(2):125-8.

12. BRASIL. DECRETO-LEI 51.838,14 de março de 1963. Normas para o controle da Leishmaniose Brasil.

13. Silva SP, Marques LFV, Lamounier KC, Castro JM, Borja-Cabrera G. Leishmaniose visceral humana: reflexões éticas e jurídicas acerca do controle do reservatório canino no Brasil. Rev Bio y Der. 2017; 39:135-51.

14. Alvar J, Vélez ID, Bern C, Herrero M, Desjeux P, Cano J. Leishmaniasis worldwide and global estimates of its incidence. PloS ONE. 2012; 7(5):e35671.

15. Castro JM, Rodrigues SM, Tarso S, Costa FL, Rodrigues ACCP, Vieira LDF et al. Conhecimento, percepções de indivíduos em relação à leishmaniose visceral humana como novas ferramentas de controle. Ensaios Cienc Cienc Biol Agrar Saúde. 2016; 20(2):93-103.

16. Zuben APB, Donalísio MR. Dificuldades na execução das diretrizes do Programa de Vigilância e Controle da Leishmaniose Visceral em grandes municípios brasileiros. Cad Saúde Pública. 2016; 32(6):e00087415.

17. Vieira T, Martines R, Ferreira CM, Cardoso JA, Falcão GGVSC, Farias JG. Lesões de paracoccidioidomicose acometendo tecido cutâneo e mucosa bucal: relato de caso clínico. Rev Bahiana Odonto. 2013; 4(1):54-64.

18. Martins RJ, Carloni MEOG, Moimaz SAS, Garbin CAS, Garbin AJI. Dentists' knowledge and experience regarding leprosy in an endemic area in brazil. Rev Inst Med Trop Sao Paulo. 2016; 58:76.

19. Castling B, Layton SA, Pratt RJ. Cutaneous leishmaniasis. An unusual cause of facial swelling. Oral Surg Oral Med Oral Pathol. 1994; 78(1):91-2.

20. Amin M, Manisali M. Cutaneous Leishmaniasis Affecting the Face: Report of a Case. J Oral Maxillofac Surg. 2000; 58(9):1066-9.

21. Sampaio RNR, Salaro CP, Resende P, Paula CDR. Leishmaniose tegumentar americana associada à AIDS: relato de quatro casos. Rev Soc Bras Med Trop. 2002; 35(6):651-4.

22. Lobo KS, Bezerra JMT, Brito LMO, Silva JS, Pinheiro VCS. Conhecimentos de estudantes sobre Leishmaniose Visceral em escolas públicas de Caxias, Maranhão, Brasil. Ciênc saúde coletiva. 2013; 18(8):2295-300.

\section{CONFLITO DE INTERESSES}

Os autores declaram não haver conflitos de interesse.

\section{AUTOR PARA CORRESPONDÊNCIA}

\section{Cléa Adas Saliba Garbin}

cgarbin@foa.unesp.br

Submetido em 04/05/2017

Aceito em 08/07/2017 